\title{
Antimicrobial Activity of Various Parts of Tomato Plants Varied with Different Solvent Extracts
}

\author{
Dong Sub Kim ${ }^{1}$, Yurina Kwack ${ }^{2}$, Jung Heon Lee ${ }^{1}$, and Changhoo Chun (iD) ${ }^{1,3 *}$ \\ ${ }^{1}$ Department of Plant Science, Seoul National University, Seoul 08826, Korea \\ ${ }^{2}$ Division of EcoDivision of Eco-friendly Horticulture, Yonam College, Cheonan 31005, Korea \\ ${ }^{3}$ Research Institute of Agriculture and Life Sciences, Seoul National University, Seoul 08826, Korea
}

(Received on July 20, 2018; Revised on November 8, 2018; Accepted on December 6, 2018)

The antimicrobial activity of acetone, hexane, dichloromethane, and methanol extracts from leaves, stems, immature green fruits, and red fruits of tomato plants was examined against six phytopathogens. The minimum inhibitory concentration (MIC) of the acetonic extracts from these four plant parts was lower than that of the other solvents. Among the acetonic extracts, tomato leaves had a lower MIC than the other tomato parts. The acetonic extract from tomato leaves was therefore selected as a source of antimicrobial substances. The acetonic extract from tomato leaves inhibited mycelial growth of Fusarium oxysporum f. sp. lycopersici, Glomerella cingulata, and Rhizoctonia solani. Mycelial growth of $R$. solani treated with acetone extract from leaves showed more susceptibility than the other phytopathogens. Using $0.31 \mathrm{mg} / \mathrm{ml}$ of the acetonic extract from leaves, mycelial growth of $R$. solani on days 1,2 , and 3 decreased by $50.0,52.1$, and $64.0 \%$, respectively, compared with acetone solvent treatment. The antimicrobial compounds effective against $R$. solani were identified as linolenic acid and caffeic acid by bioautography and GC-MS. These two compounds were used to treat six phytopathogens to confirm their antimicrobial activities. Linolenic acid inhibited mycelial growth of $R$.

\footnotetext{
*Corresponding author.

Phone) +82-2-880-4567, FAX) 82-2-873-8527

E-mail) changhoo@snu.ac.kr

ORCID

Changhoo Chun

http://orcid.org/0000-0003-0015-8150

(c) This is an Open Access article distributed under the terms of the Creative Commons Attribution Non-Commercial License (http:// creativecommons.org/licenses/by-nc/4.0) which permits unrestricted noncommercial use, distribution, and reproduction in any medium, provided the original work is properly cited.
}

Articles can be freely viewed online at www.ppjonline.org. solani, while caffeic acid showed only slight antimicrobial activity. Results indicated that we propose extracts from tomato leaves which included antimicrobial compounds may provide a new lead in the pursuit of new biological sources of agrochemical candidates.

Keywords : caffeic acid, linolenic acid, Rhizoctonia solani

Handling Editor : Sang, Mee Kyung

Since tomato fruit has been subject to metabolite analyses for several decades, a significant number of compounds, representing diverse biosynthetic pathways and covering an array of traits (from volatile to highly polar to nonpolar), have been identified. These biochemicals comprise sugars, amino acids, organic acids, fatty acids, hormones, phenolics, alkaloids, and terpenes including carotenoids and various volatile compounds (Salunkhe et al., 1974). When using high-resolution accurate mass MS coupled to $\mathrm{C}_{18}$-reverse phase LC, more than 100 secondary metabolites have been annotated in aqueous-methanol extracts of peel from ripe tomato fruits (Moco et al., 2006). With fruits at different ripening stages, about 500 compounds were detected in the cultivar 'Ever' (Moco et al., 2007), and more than 800 compounds were detected in the cultivar 'MicroTom' (Iijima et al., 2008).

Preivous researches have indicated that non-edible parts of the tomato contain a higher content of antimicrobial compounds than edible parts. For instance, tomato leaves include a higher content of antimicrobial metabolites such as chlorogenic acid, caffeic acid, vanillic acid, $\beta$-phellandrene, sabinene, $\alpha$-terpinene, dehydro-tomatine, and $\alpha$-tomatine than tomato fruits (Kim et al., 2014). A few studies have only described the activities of the metabolites from non-edible parts using various extraction methods. 
Selection of solvent is important because antimicrobial substances show different solubility depending on the polarity of the extract solvent (Østensvik et al., 1998).

The goal of this research is to identify antimicrobial activity of the extracts from tomato plant including nonedible parts and find out the antimicrobial compounds as scientific evidence for the effectiveness of the extracts.

\section{Materials and Methods}

Plant materials. 'Bacchus' tomato plants (Monsanto Korea, Jochiwon, Korea) were transplanted in a greenhouse located in Gwangju (N 35.26 $6^{\circ}$ E $126.74^{\circ}$ ), Korea, on August 19, 2011. Their leaves, stems, and fruits were harvested on May 15, 2012. The fruits were classified at six ripening stages (immature green, mature green, breaker, turning, pink, light red, red, and deep red) according to USAD standards (https://ucanr.edu/repository/ view.cfm? article $=83755 \% 20 \&$ groupid $=9$ ). The fruits of immature green and red stages were selected for this study. Samples at each stage were separately stored at $-20^{\circ} \mathrm{C}$ until antimicrobial and phytochemical analyses were performed.

Extraction procedure. The extraction was performed according to the method of Mahlo et al. (2010). Finely ground materials of the leaves, stems, and fruits $(4 \mathrm{~g})$ were extracted with $40 \mathrm{ml}$ of hexane, dichloromethane, acetone, or methanol in polyester plastic tubes with strong shaking on a shaker for $5 \mathrm{~min}$. After centrifuging at $13,300 \mathrm{~g}$ for 5 min, the supernatants were decanted into weighed glass vials. The process was repeated three times, and the extracts were mixed. The solvents were evaporated under a stream of cold air at room temperature.

Microorganisms. Fungi and oomycetes pathogenic to tomato plants (Colletotrichum coccodes (KACC 40802), Fusarium oxysporum f. sp. lycopersici (KACC 40043), and Phytophthora capsici (KACC 40177)) and those pathogenic to strawberry plants (Glomerella cingulata (KACC 40300), Phytophthora cactorum (KACC 40183), and Rhizoctonia solani (KACC 40115)) were provided by the Genebank Information Center, Rural Development Administration, Jeonju, Korea. All microbial strains were maintained on potato dextrose (PD) agar in a chamber maintained at $25^{\circ} \mathrm{C}$ until antimicrobial and phytochemical analyses were performed.

\section{Antimicrobial assays}

Microdilution assay. The microdilution assay for antifungal activity was performed according to the method of
Masoko et al. (2005). Residues of the hexanic, dichloromethanic, acetonic, and methanolic extracts were dissolved in hexane, dichloromethane, acetone, and methanol to a concentration of $10 \mathrm{mg} / \mathrm{ml}$, respectively. The plant extracts $(100 \mu \mathrm{l})$ were repeatedly diluted in a 1:1 ratio by volume with distilled water in 96-well microtiter plates. Microbial cultures $(100 \mu \mathrm{l})$ in PD broth were added to each well. $p$-Iodonitrotetrazolium violet $(40 \mu \mathrm{l}$ at $0.2 \mathrm{mg} / \mathrm{ml})$ was dissolved in distilled water and added to each of the microtiter plate wells as an indicator of microbial growth. The covered microtiter plates were incubated for 2 to 3 days at $35^{\circ} \mathrm{C}$ and $100 \%$ relative humidity $(\mathrm{RH})$.

Agar dilution method. PD agar medium $(100 \mathrm{ml})$ was prepared with the solvents or the tomato plant extracts by adding distilled water. The mixtures were placed into Petri dishes. Mycelia of the fungi and oomycetes were placed in the center of each Petri dish and incubated in a growth chamber at $26^{\circ} \mathrm{C}$ and $50 \% \mathrm{RH}$. The mycelial diameter was measured twice with a ruler over a span of seven days, and the two measurements were averaged.

Bioautography. Bioautography using thin layer chromatography (TLC) was performed through the method of Mahlo et al. (2010). The TLC plates were loaded with 100 $\mu \mathrm{g}$ of each of the extracts in a line $10 \mathrm{~mm}$ wide. The prepared plates were developed using eluent that consisted of toluene:ethyl acetate:methanol:formic acid (6:4:2:1, v/v/v/ $v)$. The developed plates were sprayed with a concentrated suspension containing $1.0 \times 10^{6}$ cells $/ \mathrm{ml}$ of actively growing microorganisms. After overnight incubation, the plates were sprayed with a $2 \mathrm{mg} / \mathrm{ml}$ solution of $p$-iodonitrotetrazolium violet and again incubated overnight in a chamber at $35^{\circ} \mathrm{C}$ and $100 \% \mathrm{RH}$ in darkness.

GC-MS identification. The developed plates were visualized and inspected by reagents and UV lights and then used for GC-MS identification. The active compounds were scraped off and placed in vials with solvent. The vials were shaken for $10 \mathrm{~min}$ and centrifuged for separation of the compounds and silica gel. The supernatant was collected and placed in clean vials.

The GC-MS spectra were recorded on a Thermo TRACE1310 instrument equipped with Thermo ISQ LT (Thermo Fisher Scientific, Waltham, MA, USA), operating under EI mode at $70 \mathrm{eV}$. An HP-5 MS column $(30 \mathrm{~m} \times$ $0.25 \mathrm{~mm} \times 0.5 \mu \mathrm{m}$ film thickness) was used to separate the antimicrobial compounds. The temperature was set to $50^{\circ} \mathrm{C}$ for $2 \mathrm{~min}$, followed by a temperature gradient of $50-325^{\circ} \mathrm{C}$ (increasing by $10^{\circ} \mathrm{C} / \mathrm{m}$ ) and holding at $325^{\circ} \mathrm{C}$ for $10 \mathrm{~min}$. 
The injector temperature was $300^{\circ} \mathrm{C}$. The flow rate of helium as a carrier gas was $1.5 \mathrm{ml} / \mathrm{min}$. The mass spectra were deconvoluted by AMDIS ${ }^{\circledR}$ software (NIST, Gaithersburg, MD, USA). The compounds were identified by comparing their mass spectral fragmentation and retention times with those of reference compounds isolated in our laboratory or supplied from other laboratories or with standard reference spectra from the database of the National Instrumentation Center for Environmental Management, Seoul National University (Seoul, Korea).

HPLC conditions. Quantitative analysis of the antimicrobial compounds was performed using an HPLC system (Ultimate 3000, Dionex, Sunnyvale, CA, USA). A Zorbax ODS C-18 column $(150 \times 4.6 \mathrm{~mm}$ i.d. $5 \mu \mathrm{m}$; Young Jin Biochrom Co., LTD, Seongnam, Korea) was used for the analysis. The extract was filtered through a syringe filter ( $0.45 \mu \mathrm{m}$ pore size) before injection into the HPLC apparatus. The mobile phase consisted of $0.3 \%$ trifluoroacetic acid (phase A) and acetonitrile (phase B). Separation was carried out for 40 min under the following conditions: from 0 to $25 \mathrm{~min}, 90 \%$ (A) and $10 \%$ (B); from 25 to $30 \mathrm{~min}$, $40 \%$ (A) and $60 \%$ (B); from 30 to $35 \mathrm{~min}, 100 \%$ (B); from 35 to $40 \mathrm{~min}, 90 \%$ (A) and $10 \%$ (B). The eluted components were monitored using a UV/Vis detector at 280 and $340 \mathrm{~nm}$. The standard chemicals of caffeic and linolenic acids were purchased from Sigma-Aldrich.

\section{Results and Discussion}

Minimum inhibitory concentration values of different solvent extracts from various parts of tomato plants. The MIC values of extracts from tomato leaves were especially low (Table 1). Kim et al. (2014) reported that tomato leaves contain more pesticidal phenolic compounds and alkaloids than other tomato parts. Previous research has shown that leaves of other plants have antimicrobial activity against phytopathogens. For example, leaf extract of sweet William catchfly (Silene armeria L.) inhibited growth of Botrytis cinerea, Colletotrichum capsici, Fusarioum solani, F. oxysporum, Phytophthora capsici, and Rhizoctonia solani (Bajpai et al., 2008). This result is meaningful in agronomy because tomato plants are grown worldwide and harvest index of tomato is about $33 \%$ (Salisbury et al., 1997). Therefore, there may be no trouble with raw material supply and tomato farmers can earn additional income. Determination of an extract solvent was also important because MIC values of tomato leaves depend on solvent polarity. Jayaraman et al. (2008) reported that the greater antimicrobial activity of the acetone extract might be due to the higher solubility of the extract in organic solvents. Acetone, moreover, can be a solvent used for polar and non-polar compounds because its solvent strength is 5.1 (compared to a median value of 0 for hexane and 10.2 for water). The acetonic extract from tomato leaves can contain more diverse biochemicals (including antimicrobial compounds) than the solvent extracts of the other tomato parts. Therefore, the acetonic extract from tomato leaves could be most useful as an antimicrobial agent.

The acetonic extract from tomato leaves showed antimicrobial activity against all six pathogens. Among the phytopathogens, Rhizoctonia solani was the most susceptible to the acetonic extract from tomato leaves, with an MIC less than $0.31 \mathrm{mg} / \mathrm{ml}$ (Table 1). Previous research has also shown that certain plant extracts show antifungal activities against $R$. solani (Castillo et al., 2010; Jasso de Rodríguez et al., 2007; Osorio et al., 2010; Tapwal et al., 2011). Likely candidates for antimicrobial compounds active against $R$. solani are phenolic acids (Francisco and Cooper-Driver, 1984), isoflavonoids (Smith, 1976;

Table 1. Minimum inhibitory concentrations (MIC) of extracts from tomato plants with various solvents against six pathogenic microorganisms

\begin{tabular}{|c|c|c|c|c|c|c|c|c|c|c|c|c|c|c|c|c|}
\hline \multirow{3}{*}{ Microorganism } & \multicolumn{16}{|c|}{ Average MIC (mg/ml) } \\
\hline & \multicolumn{4}{|c|}{ Leaf } & \multicolumn{4}{|c|}{ Internodal stem } & \multicolumn{4}{|c|}{ Immature green fruit } & \multicolumn{4}{|c|}{ Red fruit } \\
\hline & $\mathrm{H}^{\mathrm{z}}$ & $\mathrm{D}$ & $\mathrm{A}$ & M & $\mathrm{H}$ & $\mathrm{D}$ & A & M & $\mathrm{H}$ & $\mathrm{D}$ & A & M & $\mathrm{H}$ & $\mathrm{D}$ & A & M \\
\hline C. coccodes & $>5.00$ & 2.50 & 2.50 & 2.50 & $--^{y}$ & 2.50 & - & 2.50 & $>5.00$ & 2.50 & 2.50 & 2.50 & $>5.00$ & 2.50 & 2.50 & 2.50 \\
\hline F. oxysporum & 2.50 & 1.25 & 1.25 & 1.25 & - & 1.25 & - & 2.50 & 2.50 & 1.25 & 2.50 & 5.00 & 1.25 & 1.25 & 2.50 & 2.50 \\
\hline G. cingulata & 5.00 & 1.25 & 1.25 & 1.25 & - & 5.00 & - & 5.00 & 5.00 & 5.00 & 1.25 & 2.50 & 5.00 & 1.25 & 5.00 & 5.00 \\
\hline R. solani & 1.25 & 1.25 & $<0.31$ & 1.25 & - & 2.50 & - & 2.50 & 2.50 & 1.25 & 5.00 & 5.00 & 2.50 & 1.25 & 5.00 & 5.00 \\
\hline P. cactorum & $>5.00$ & 1.25 & 1.25 & 1.25 & - & 2.50 & - & 5.00 & $>5.00$ & 1.25 & 2.50 & 2.50 & 2.50 & 1.25 & 1.25 & $<0.31$ \\
\hline P. capsici & $>5.00$ & $>5.00$ & 1.25 & 2.50 & - & $>5.00$ & - & $>5.00$ & $>5.00$ & 5.00 & 5.00 & 2.50 & $>5.00$ & 5.00 & 2.50 & 2.50 \\
\hline
\end{tabular}

${ }^{\mathrm{z}} \mathrm{H}$, hexane; D, dichloromethane; A, acetone; M, methanol

y-, not obtained. 


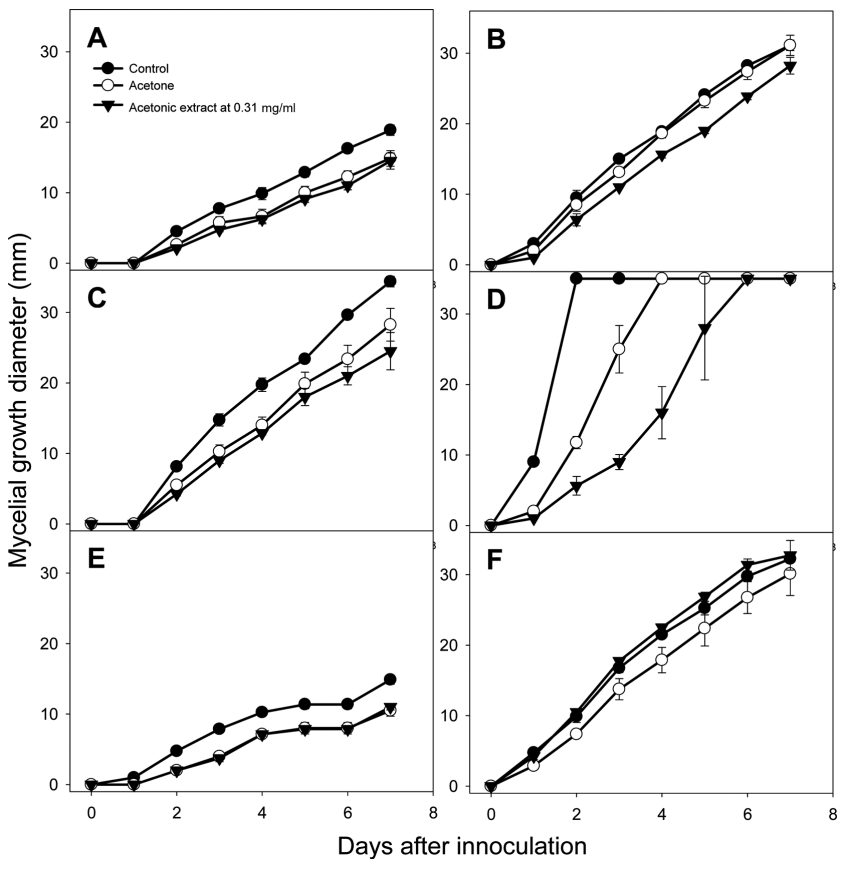

Fig. 1. Inhibitory effect of acetonic extract from tomato leaves on mycelial growth of six microorganisms. (A) Colletotrichum coccodes; (B) Fusarium oxysporum; (C) Glomerella cingulata; (D) Rhizoctonia solani, (E) Phytophthora cactorum; (F) P. capsici. Vertical bars represent standard errors of the means.

Weidenbörner et al., 1990), saponins (Kuo et al., 2010), monoterpenes (Kordali et al., 2008), alkaloids (AbdelMotaal et al., 2010), or fatty acids (Walters et al., 2004). Tomato leaves contain diverse secondary metabolites including phenolic acids, monoterpenes, alkaloids (Kim et al., 2014), and fatty acids (Conconi et al., 1996). In addition, phenolic compounds and fatty acids are generally extracted with acetone (Krygier et al., 1982; Rouser et al., 1967). These results indicate that the acetonic extract of tomato leaves might include antimicrobial phenolic acids and/or fatty acids.

Inhibitory effects of the acetonic extracts from tomato leaves on mycelial growth of various fungi. The acetonic extract from tomato leaves inhibited mycelial growth of Fusarium oxysporum, Glomerella cingulata, and Rhizoctonia solani compared to acetone solvent treatment (Fig. 1). F. oxysporum, $G$. cingulata, and $R$. solani are ubiquitous soil inhabitants that can colonize plant roots, stems, and leaves, suggesting that the acetonic extract from tomato leaves can be used as a soil disinfectant. Among these three fungi, mycelial growth of $R$. solani was most strongly inhibited by the acetonic extract of tomato leaves, and this fungus provided the extract's lowest MIC value: with $0.31 \mathrm{mg} / \mathrm{ml}$ of extract, mycelial growth of $R$. solani on days 1,2 , and 3 decreased by $50.0,52.1$, and $64.0 \%$, respectively, compared with acetone solvent treatment (Fig. 1). This result demonstrated the inhibitory effect of the acetonic extract from tomato leaves on mycelial growth of $R$. solani over time.

Composition and activity of antimicrobial compounds in acetonic extracts from tomato leaves. During TLC-direct bioautography detection for antimicrobial compounds from the acetonic extracts of tomato plant, so-called inhibition zones (creamy and white areas) were found around all tested microorganisms exposed to the acetonic extracts of tomato leaves and red fruits (Fig. 2). The acetonic extracts of tomato leaves possessed 1-2 antimicrobial compounds
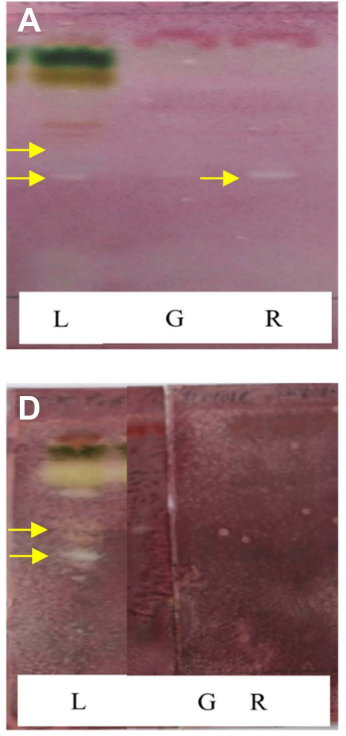
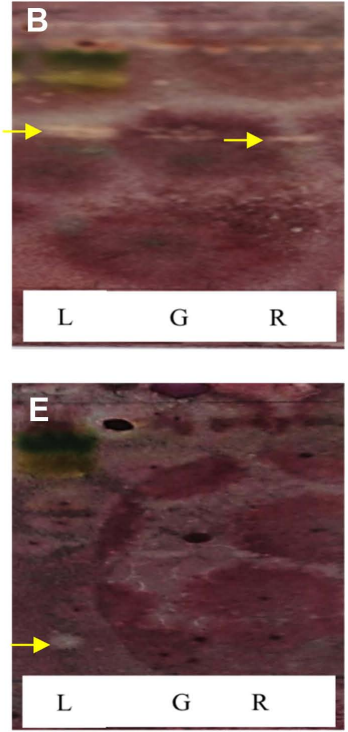
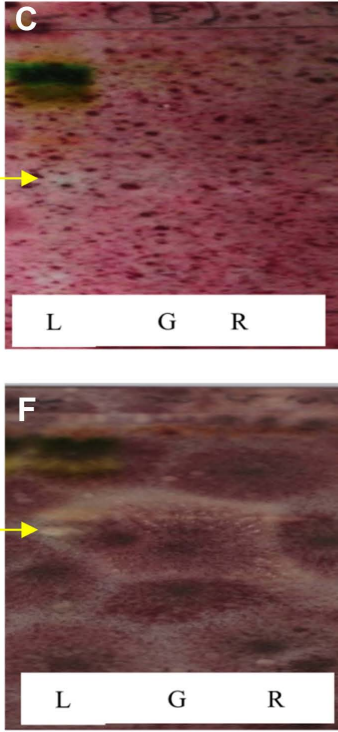

Fig. 2. Bioautogram of acetonic extracts from leaves $(\mathrm{L})$, immature green fruits $(\mathrm{G})$, and red fruits $(\mathrm{R})$ of tomato plants. White areas indicate inhibition of microbial growth. (A) Colletotrichum coccodes; (B) Fusarium oxysporum; (C) Glomerella cingulata; (D) Rhizoctonia solani; (E) Phytophthora cactorum; (F) P. capsici. 

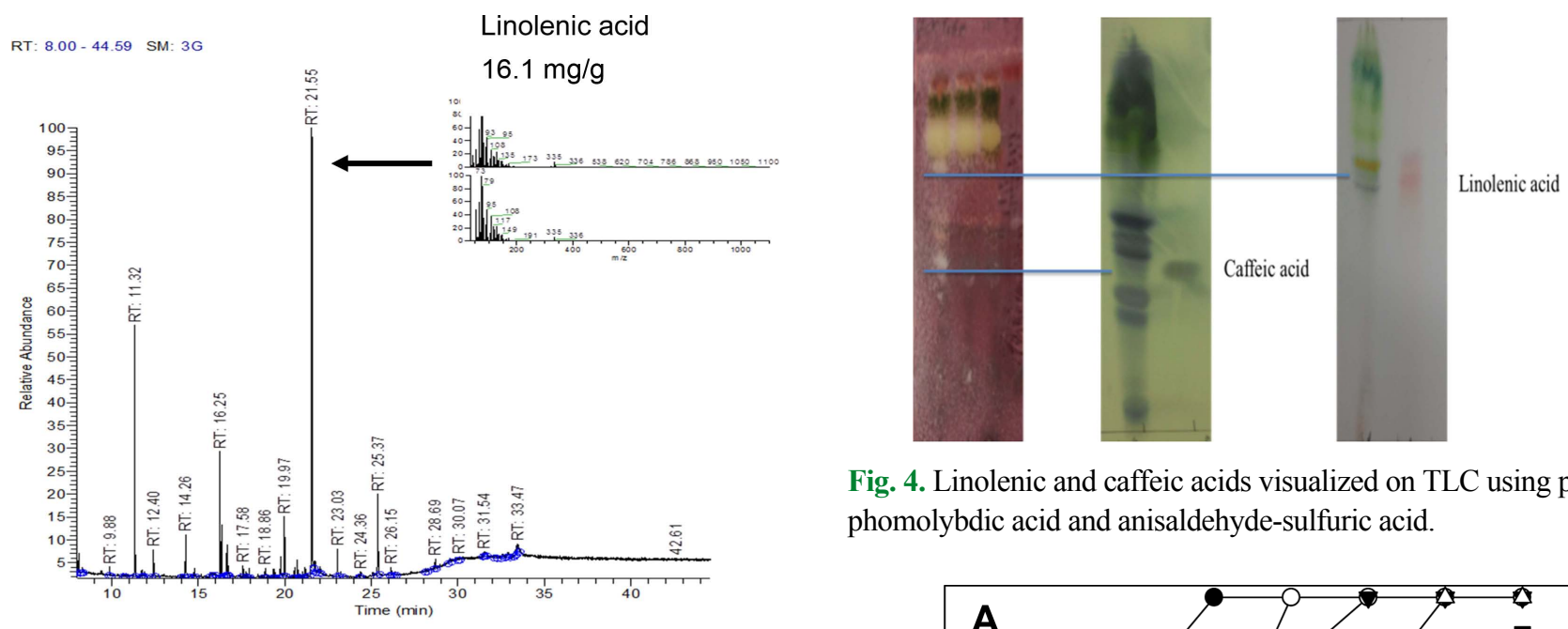

Fig. 4. Linolenic and caffeic acids visualized on TLC using phosphomolybdic acid and anisaldehyde-sulfuric acid.

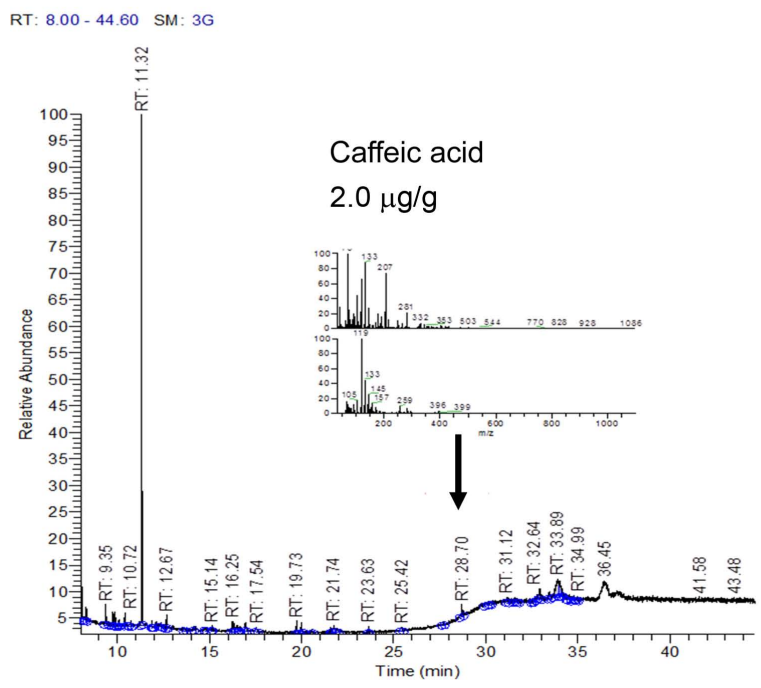

Fig. 3. GC-MS chromatogram of preparative TLC-isolated compounds in acetonic extract from tomato leaves.

for all of the microbial species used in this study, while the extracts of red fruits contained only one compound for Colletotrichum coccodes and Fusarium oxysporum, R. solani, the microorganism most susceptible to the acetonic extracts from tomato leaves, showed two inhibition zones. GCMS analysis revealed that the antifungal compounds in the two inhibition zones were linolenic acid and caffeic acid. Specifically, linolenic acid at $16.1 \mathrm{mg} / \mathrm{g}$ and caffeic acid at $2.0 \mu \mathrm{g} / \mathrm{g}$ were found to be the dominant compounds in both inhibition zones by HPLC analysis (Fig. 3). Linolenic acid and caffeic acid were also visualized on a TLC plate and migrated the same distance as the antimicrobial compounds in phosphomolybdic or anisaldehyde-sulfuric acid (Fig. 4). Conconi et al. (1996) reported that linolenic acid, an acetone-soluble lipid, is a major component of the total lipids in tomato leaves. Even though it is not a secondary metabolite, its antimicrobial activity has often been dem-

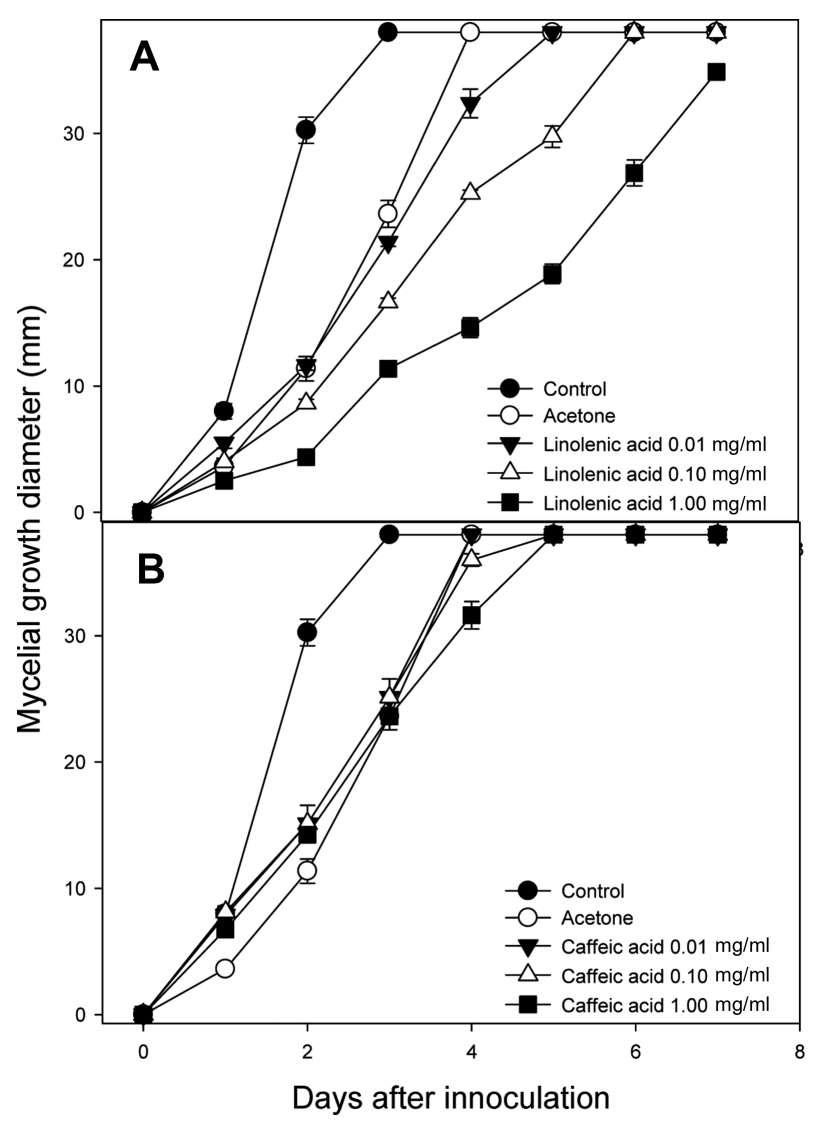

Fig. 5. Inhibitory effect of linolenic (A) and caffeic acids (B) on mycelial growth of Rhizoctonia solani. Vertical bars represent standard errors of the means.

onstrated. For instance, Walters et al. (2004) reported that linolenic acid decreased mycelial growth and fungal biomass of R. solani, Pythium ultimum, Pyrenophora avenae, and Crinipellis perniciosa. Hamberg (1999) reported that linolenic acid was a substrate for the production of a range of trihydroxy oxylipins known to possess antifungal activity. San Francisco and Cooper-Driver (1984) confirmed that caffeic acid showed antifungal activity against fungi 
(R. solani, Pythium debaryanum, P. middletonii, and $P$. ultimum) and bacteria (Corynebacterium poinsettiae, $C$. fasciens, Erwinia amylovora, and E. carotovora).

With linolenic acid at $1.00 \mathrm{mg} / \mathrm{ml}$, mycelial growth of $R$. solani on day 3 was reduced by $51.9 \%$ compared with acetone solvent treatment. Walters et al. (2004) reported that linolenic acid at 100 and $1,000 \mu \mathrm{M}$ decreased mycelial growth of $R$. solani by 51.2 and $69.8 \%$, respectively. Caffeic acid at 0.10 and $1.00 \mathrm{mg} / \mathrm{ml}$ inhibited the mycelial growth of $R$. solani on day 4 (Fig. 5). Al-Mughrabi et al. (2001) also reported that caffeic acid showed weak antifungal activity against $R$. solani. These results indicate that linolenic acid and caffeic acid from tomato extracts are antimicrobial compounds against $R$. solani, and that these two substances can be used in commercial products as natural antifungal agents.

\section{Conclusion}

In MIC tests, the acetonic extracts from tomato leaves had the greatest antimicrobial activity against the tested phytopathogenic microorganisms. Among the tested phytopathogens, Rhizoctonia solani showed significantly inhibited mycelial growth after application of the acetonic extract from tomato leaves. Based on the bioautography results, linolenic acid and caffeic acid were found to be effective antimicrobial compounds against $R$. solani. These results demonstrate the potential of tomato leaves as a source of extracts or pure compounds with activity against $R$. solani and other fungal phytopathogens. Profiling and MIC results showed that other parts of the tomato plant also contained antimicrobial compounds, but their antimicrobiotic activities were comparatively lower. Together, our results suggest that tomato leaves, a major non-edible plant part that can be collected after training branches and at the end of cultivation, are a potential source of natural antimicrobial agents. Moreover, we found out the major antimicrobial compounds in the extract from tomato leaves in this study. This result can be scientific evidence for the antimicrobial activity of the extract.

\section{Acknowledgments}

This study was supported by Rural Development of Administration (C.C. PJ010822). The URL is [http://atis.rda. go.kr/rdais/main/main.vw].

\section{References}

Abdel-Motaal, F. F., El-Zayat, S. A., Kosaka, Y., El-Sayed, M.
A., Kashima, R., Maeda, Y., Nassar, M. S. M. and Ito, S. 2010. Antifungal activities of hyoscyamine and scopolamine against two major rice pathogens: Magnaporthe oryzae and Rhizoctonia solani. J. Gen. Plant Pathol. 76:102-111.

Al-Mughrabi, K., Aburjai, T. A., Anfoka, G. H. and Shahrour, W. 2001. Antifungal activity of olive cake extracts. Phytopathol. Mediterr. 40:240-244.

Bajpai, V. K., Shukla, S. and Kang, S. C. 2008. Chemical composition and antifungal activity of essential oil and various extract of Silene armeria L. Bioresour. Technol. 99:8903-8908.

Castillo, F., Hernández, D., Gallegos, G., Mendez, M., Rodrîguez, R., Reyes, A. and Aguilar, C. N. 2010. In vitro antifungal activity of plant extracts obtained with alternative organic solvents against Rhizoctonia solani Kühn. Ind. Crops Prod. 32:324-328.

Conconi, A., Miquel, M., Browse, J. A. and Ryan, C. A. 1996. Intracellular levels of free linolenic and linoleic acids increase in tomato leaves in response to wounding. Plant Physiol. 111:797-803.

Hamberg, M. 1999. An epoxy alcohol synthase pathway in higher plants: biosynthesis of antifungal trihydroxy oxylipins in leaves of potato. Lipids 34:1131-1142.

Iijima, Y., Nakamura, Y., Ogata, Y., Tanaka, K., Sakurai, N., Suda, K., Suzuki, T., Suzuki, H., Okazaki, K., Kitayama, M., Kanaya, S., Aoki, K. and Shibata, D. 2008. Metabolite annotations based on the integration of mass spectral information. Plant $J$. 54:949-962.

Jasso de Rodríguez, D. J., Hernández-Castillo, D., Angulo-Sánchez, J. L., Rodríguez-García, R., Villarreal Quintanilla, J. A. and Lira-Saldivar, R. H. 2007. Antifungal activity in vitro of Flourensia spp. extracts on Alternaria sp., Rhizoctonia solani, and Fusarium oxysporum. Ind. Crops Prod. 25:111-116.

Jayaraman, S., Manoharan, M. S. and Illanchezian, S. 2008. Invitro antimicrobial and antitumor activities of Stevia rebaudiana (Asteraceae) leaf extracts. Trop. J. Pharm. Res. 7:11431149.

Kim, D. S., Na, H., Kwack, Y. and Chun, C. 2014. Secondary metabolite profiling in various parts of tomato plants. Korean J. Hortic. Sci. Technol. 32:252-260.

Kordali, S., Cakir, A., Ozer, H., Cakmakci, R., Kesdek, M. and Mete, E. 2008. Antifungal, phytotoxic and insecticidal properties of essential oil isolated from Turkish Origanum acutidens and its three components, carvacrol, thymol and $p$-cymene. Bioresour. Technol. 99:8788-8795.

Krygier, K., Sosulski, F. and Hogge, L. 1982. Free, esterified, and insoluble-bound phenolic acids. 1. Extraction and purification procedure. J. Agric. Food Chem. 30:330-334.

Kuo, P. C., Lin, T. C., Yang, C. W., Lin, C. L., Chen, C. F. and Huang, J. W. 2010. Bioactive saponin from tea seed pomace with inhibitory effects against Rhizoctonia solani. J. Agric. Food Chem. 58:8618-8622.

Mahlo, S. M., McGaw, L. J. and Eloff, J. N. 2010. Antifungal activity of leaf extracts from South African trees against plant pathogens. Crop Prot. 29:1529-1533. 
Masoko, P., Picard, J. and Eloff, J. N. 2005. Antifungal activities of six South African Terminalia species (Combretaceae). J. Ethnopharmacol. 99:301-308.

Moco, S., Bino, R. J., Vorst, O., Verhoeven, H. A., de Groot, J., van Beek, T. A., Vervoort, J. and de Vos, C. H. 2006. A liquid chromatography-mass spectrometry-based metabolome database for tomato. Plant Physiol. 141:1205-1218.

Moco, S., Capanoglu, E., Tikunov, Y., Bino, R. J., Boyacioglu, D., Hall, R. D., Vervoort, J. and de Vos, C. H. 2007. Tissue specialization at the metabolite level is perceived during the development of tomato fruit. J. Exp. Bot. 58:4131-4146.

Osorio, E., Flores, M., Hernández, D., Ventura, J., Rodríguez, R. and Aguilar, C. N. 2010. Biological efficiency of polyphenolic extracts from pecan nuts shell (Carya illinoensis), pomegranate husk (Punica granatum), and creosote bush leaves (Larrea tridentata Cov.) against plant pathogenic fungi. Ind. Crops Prod. 31:153-157.

Østensvik, Ø., Skulberg, O. M., Underdal, B. and Hormazabal, V. 1998. Antibacterial properties of extracts from selected planktonic freshwater cyanobacteria - a comparative study of bacterial bioassays. J. Appl. Microbiol. 84:1117-1124.

Rouser, G., Kritchevsky, G., Simon, G. and Nelson, G. J. 1967. Quantitative analysis of brain and spinach leaf lipids employing silicic acid column chromatography and acetone for elution of glycolipids. Lipids 2:37-40.
Salisbury, F. B., Gitelson, J. I. and Lisovsky, G. M. 1997. Bios3: Siberian experiments in bioregenerative life support. BioScience 47:575-585.

Salunkhe, D. K., Jadhav, S. J. and Yu, M. H. 1974. Quality and nutritional composition of tomato fruit as influenced by certain biochemical and physiological changes. Qual. Plant. 24:85-113.

San Francisco, M. and Cooper-Driver, G. 1984. Anti-microbial activity of phenolic acids in Pteridium aquilinum. Amer. Fern J. 74:87-96.

Smith, D. A. 1976. Some effects of the phytoalexin, kievitone, on the vegetative growth of Aphanomyces euteiches, Rhizoctonia solani and Fusarium solani f. sp. phaseoli. Physiol. Plant Pathol. 9:45-48.

Tapwal, A., Garg, S., Gautam, N. and Kumar, R. 2011. In vitro antifungal potency of plant extracts against five phytopathogens. Braz. Arch. Biol. Technol. 54:1093-1098.

Walters, D., Raynor, L., Mitchell, A., Walker, R. and Walker, K. 2004. Antifungal activities of four fatty acids against plant pathogenic fungi. Mycopathologia 157:87-90.

Weidenbörner, M., Hindorf, H., Jha, H. C., Tsotsonos, P. and Egge, H. 1990. Antifungal activity of isoflavonoids in different reduced stages on Rhizoctonia solani and Sclerotium rolfsii. Phytochemistry 29:801-803. 